\title{
Del gaucho literario al gaucho "real": un aporte a su construcción en Argentina (1845-1913)*
}

\author{
From Literary Gaucho to "Real" Gaucho: A Contribution to Its \\ Construction in Argentina (1845-1913)
}

\author{
Máximo Yolis \\ maxiyol@gmail.com \\ Maestrando \\ Universidad Nacional de Tres de Febrero \\ Melián 3680 \\ C1430EYX - Buenos Aires \\ Argentina
}

\begin{abstract}
Resumen
En este artículo se analiza cómo las élites de Argentina llevaron a cabo la construcción del gaucho, entre 1845 y 1913, cuando fue reivindicado como representante de la "identidad nacional" y cómo dicha construcción dio nacimiento a ejemplares "reales" de ese habitante tradicional de las pampas. Para ello, se utilizan las tesis de Ian Hacking acerca de las "clases de gente interactivas". Tomando como base fuentes literarias de las élites argentinas y de viajeros extranjeros, se concluye que en 1845 el "gaucho" no era una forma de ser un tipo de persona, pero en 1913 conformaba todo un conglomerado de experiencias y formas de autocomprensión y de vida en sociedad que algunas personas, habitantes de zonas rurales principalmente, se atribuían a sí mismas. Se estudia el trayecto del término "gaucho", cuya valoración positiva hará posible su "redención"; y su extinción, estrategia discursiva de viajeros y élites, que permitirá a un grupo de personas considerarse como los últimos representantes del gaucho, abriéndose, así, para ellos nuevas posibilidades de acción.
\end{abstract}

\section{Palabras clave}

Construccionismo; Identidad nacional; Gaucho.

\begin{abstract}
This article analyzes the construction of the Gaucho-figure by the Argentine elites between 1845 and 1913, when it was finally proclaimed as a symbol of "national identity", and how this construction gave birth to "real" specimens of the traditional dweller of the Argentine pampas. To this end, Ian Hacking's theses on "interactive kinds of people" are used. By the study of literary sources of the Argentine elites and foreign travelers, it is found that in 1845, the "Gaucho" was not a way of being a type of person; but in 1913, it did mean a composite of experiences and modes of self-understanding and of life in society that some persons, mainly dwellers of the rural areas, attributed to themselves. Two aspects are studied: the trajectory of the term "Gaucho", which positive connotation allowed its "redemption"; and its extinction as a discursive strategy of travelers and elites, which would allow a group of people to consider themselves as the last examples of the gaucho, thus opening for them new possibilities of action.
\end{abstract}

\section{Keywords}

Constructionism; National identity; Gaucho.

\section{Recibido el: 31/8/2014}

Aprobado el: 10/11/2014

\footnotetext{
${ }^{*}$ Este trabajo no hubiera sido posible sin los aportes y el apoyo de la Dra. Verónica Tozzi. Se agradece a ella y a los sucesivos referís anónimos que lo enriquecieron.
} 
El gaucho, tipo representativo de la identidad argentina, ha sido objeto de un estudio más o menos sostenido desde hace ya varias décadas. Se acepta por lo común una descripción general de su conducta y sus características que permanece más o menos idéntica a lo largo de los años y los testimonios desde la época colonial hasta fines del siglo xIX. Una descripción tardía basta como ejemplo:

Especie de caballeros andantes, han cruzado muchas veces grandes extensiones de la República [...] buscando trabajo aquí y allá, asentándose como las golondrinas en un punto para permanecer un tiempo dado, después del cual, vuelven a sentir la imperiosa necesidad de cambiar de pago, y así sucesivamente, llevando su vida errante y llena de aventuras, sin techo ni hogar, hasta que al fin una reyerta de pulpería o cualquier otra circunstancia, los eliminan del cuadro de los vivos (AMBROSETTI 1893$, p. 80$) \cdot{ }^{1}$

Se trataría, entonces, de un personaje rural nómade, de ocupación imprecisa y cambiante, visitante habitual de las tabernas de la campaña de la zona rioplatense, las "pulperías", para saciar allí su sed con alcohol o abastecerse de sus "vicios", como el tabaco, y protagonista de una vida de aventuras que muchas veces lo lleva a la delincuencia.

Con los cambios de las condiciones productivas rurales, el gaucho habría encontrado imposible su supervivencia y se habría, finalmente, extinguido. El temor de que la inmigración masiva a la Argentina pusiera en peligro una pretendida esencia del "ser nacional" habría llevado a que fuera reivindicado como símbolo de aquél:

Los cambios sociales y económicos sobrevenidos en las últimas décadas del siglo anterior [XIX] condenan al exilio al gaucho real. Circunstancia que aprovechan para conformar un gaucho ideal, representativo de la nacionalidad, cuantos temen que ésta se diluya ante el incremento de la ola inmigratoria (BOSCH 1969, p. 7).

A pesar de lo generalizada que se encuentra esta descripción en obras académicas y de divulgación, el personaje tradicional de las pampas representa un caso curioso de la historiografía. Para estudiarlo, se carece prácticamente de testimonios directos de alguno de sus representantes, puesto que sólo en muy contadas ocasiones uno de ellos se reconoce como tal. ${ }^{2}$ Por otro lado, abundan sus descripciones por personas más o menos ajenas al ámbito rural y, en ellas, el gaucho siempre es un "otro", ${ }^{3}$ con características diferenciales bien marcadas. Estos testimonios pertenecen, casi en su totalidad, al género literario: se habla del gaucho, entre otros, en poesías escritas por autores "letrados", en ensayos

\footnotetext{
${ }^{1}$ Se refiere al "rumbeador", uno de los tipos de gaucho que distingue el autor.

2 En una enumeración de los sentidos de la palabra "gaucho" que incluye en su obra, Ariel de la Fuente sólo cita un testimonio directo de un "habitante de la campaña" que lo utiliza para referirse a sí mismo y, en este caso, se trata de un caudillo en correspondencia con "otra figura influyente de la política nacional" (DE LA FUENTE 2000, p. 75).

${ }^{3}$ Esta característica, de todos modos, no es exclusiva de los habitantes urbanos. El gaucho es un "otro" para los mismos habitantes de la campaña, que "la mayoría de las veces [...] usaban la palabra de otra forma: gauchos eran aquellos involucrados en el abigeato o cualquier otra forma de crimen" (DE LA FUENTE 2000, p. 76). Se retomará este tema más adelante.
} 
políticos, en estudios nostálgicos del pasado, en comentarios sobre la economía rural y, sobre todo también, en relatos de viajeros extranjeros que recorren el país. Esos testimonios comparten una característica que se ha atribuido específicamente a los informes literarios de visitantes británicos a la Argentina sobre los "indios": "las descripciones [...] categorizan, objetifican y comoditizan lo observado" (JONES 1986, p. 201, traducción nuestra). ${ }^{4}$

Así, no es sorprendente que la historiografía haya llegado a la conclusión de que nuestro concepto del gaucho ha sido en gran medida construido. Por un lado, se cuestionó la existencia de condiciones socioeconómicas que permitieran el surgimiento de ese tipo de habitantes en la campaña colonial con las características propias de lo que se conoció posteriormente como "gaucho". 5 Por otro, simultáneamente, se planteó que el gaucho mismo parecía ser objeto de una construcción: se concluyó que "mientras se fabricaba el gaucho en la realidad, también se lo empezaba a fabricar en la ficción, para justificar la ofensiva proletarizadora y militarizadora de la época" rosista: el gaucho sería, en suma, fruto "de una creación literaria y discursiva que fue muy útil para ciertos sectores de la sociedad argentina" (GELMAN 1995, p. 34, 36).

Surgieron, entonces, diversos estudios acerca de la construcción de que fue objeto el gaucho a lo largo de la historia, cuya relevancia parece incrementarse en la medida en que se descubre que "invenciones" por el estilo se han dado contemporáneamente en diferentes tradiciones de tipos equivalentes a la del personaje característico argentino (OLIVEN 2002; 2000; BARR MELEJ 1998).

Muchos de esos estudios hicieron aportes fundamentales para aprehender la utilización de la esencia del gaucho por parte de la cultura "letrada" a partir de comienzos del siglo xx como forma de rescatar una "esencia nacional" frente a las oleadas inmigratorias contemporáneas (DELANEY 1996; Cf. CHEIN 2010). Otros, centrándose específicamente en el proceso de construcción, nos permiten comprenderla como fruto de una "negociación", o tensión, entre esa cultura "letrada" y la "popular" a partir de fines del siglo xIX (EUJANIAN; CATTARUZZA 2003; PRIETO 1988).

Dos aspectos comunes a esos trabajos se prestan al debate: en primer lugar, desde lo hermenéutico, en ellos aparece la idea de que la creación del gaucho fue un proceso eminentemente cultural. El gaucho habría sido producto de una "construcción" de uno o más sectores de la sociedad. El segundo aspecto compartido por esos estudios es heurístico: en esas obras, se data la utilización del gaucho por la "alta" cultura, o el debate por su utilización entre ella y la cultura "popular", recién a fines del siglo XIX o comienzos del XX.

En cuanto al primer punto, de carácter especialmente interpretativo, parece insuficiente abordar el surgimiento del gaucho desde el "construccionismo social". Si bien es indudable que el habitante tradicional de las pampas fue fruto de una elaboración discursiva, esta perspectiva es insuficiente para explicar la

\footnotetext{
4 "Descriptions in those accounts [...] categorized, objectified, and commoditized the observed".

${ }^{5}$ Lo dicho resume el resultado de un debate historiográfico en que tomaron parte Carlos Mayo, Samuel Amaral, Juan Carlos Garavaglia y Jorge Gelman en 1987. Para una revisión integral de la bibliografía sobre este tema y las conclusiones alcanzadas, véase GARAVAGLIA; GELMAN 1995.
} 
evidencia disponible: en efecto, ella nos impone dar cuenta de la existencia, a partir de comienzos del siglo xx, de un grupo de personas que se consideraban a sí mismos representantes del tipo gaucho. Ambos procesos, creación discursiva por un lado y existencia "real" por el otro, están indudablemente relacionados. Sin embargo, desde ese punto de vista parece imposible explicar esa relación. Más en general, el "construccionismo" no puede explicar por qué, cómo y a partir de cuándo ese personaje comenzó a existir "realmente".

Luego, otro aspecto discutible del punto de vista habitual en los estudios sobre el gaucho es la datación del proceso de su utilización literaria. En general, se ubica ese comienzo a fines del siglo xIX: la "construcción social" del gaucho se habría iniciado, como muy temprano, en el último tercio del siglo, con la publicación del Martín Fierro. Sin embargo, esa perspectiva no tiene en cuenta la evidencia, que demuestra que la utilización literaria del gaucho había sido planificada por la "alta" cultura ya desde fines de la época rosista, como se verá. Por otra parte, las características que habría asumido el gaucho "real", aparentemente desde la publicación del Martín Fierro, habían sido producto de un consenso "letrado" previo: en la obra de José Hernández, el protagonista no innova sobre lo que se entendía por gaucho contemporáneamente, sino que simplemente tematiza esa convención. Los rasgos distintivos del personaje habían sido definidos ya antes del último cuarto del siglo xIX y no serían modificados con posterioridad, ni siquiera con ocasión de su "redención" por la "alta" cultura.

El proceso de construcción del gaucho tiene, entre otros, dos hitos salientes: 18 el primero, la aparición del Facundo, de Domingo Faustino Sarmiento, en 1845. Un segundo momento fundamental se da en 1913, con el intento de imponer al habitante de las pampas como arquetipo de nuestra nacionalidad a partir de las conferencias que el escritor Leopoldo Lugones ofreciera en el teatro Odeón de Buenos Aires sobre el Martín Fierro de José Hernández. ${ }^{6}$

El propósito del presente artículo es estudiar la forma en que se construyó el concepto de "gaucho" precisamente en los años que median entre el Facundo y la canonización nacional del personaje con la publicación de El payador en 1916. Es ese proceso el que permite comprender, por un lado, cómo, de una construcción puramente literaria, es posible llegar a la constitución de un gaucho "real" y, por otro, con qué condiciones de posibilidad contó la "redención" del gaucho de comienzos del siglo $x x$.

Para ello, se propone una nueva matriz hermenéutica, basada en la teorización sobre "clases de gente" formulada por Ian Hacking, y una nueva valoración de fuentes relevantes para el tema, que permiten encontrar antecedentes de la "redención" del gaucho muy anteriores a los propuestos por los enfoques historiográficos reseñados.

En cuanto a lo hermenéutico, se debe explicar la aparición del "gaucho" encarnado en sujetos concretos del Río de la Plata a partir de una creación discursiva, lo que parece difícil de lograr desde una perspectiva "construccionista". Para hacerlo, se partirá de los análisis acerca de las "clases de gente" (kinds

\footnotetext{
${ }^{6}$ Estas conferencias fueron editadas posteriormente con el título de El payador.
} 
of people) planteados por Ian Hacking (HACKING 1999; 1995; 1998). Hacking sostiene que las ciencias ( $y$, en particular, las que él denomina "ciencias humanas") son capaces de crear "clases de gente" que no existían previamente. Para ello, es necesaria la interacción de cinco elementos, a saber: (a) una clasificación; (b) las personas así clasificadas; (c) instituciones a cargo de conocer y controlar y, eventualmente, "ayudar" a esas personas; (d) un conocimiento que sustente la clasificación y defina el tipo de persona, formando presupuestos básicos sobre ellas aunque no sean ciertos; $y$, finalmente, (e) expertos que se ocupen de ese tipo de personas. Pero eso no es todo: en oposición al "construccionismo social", Hacking agrega que la clasificación creada a su vez interactúa con la gente clasificada y permite que esa gente se vea modificada por dicha clasificación, creándose entonces un "efecto bucle" (looping effect): los sujetos comienzan a verse a sí mismos como parte de una "clase de gente", lo que les permite reconsiderarse a sí mismos y a quienes los clasifican (HACKING 2007).

Así, podríamos considerar al gaucho como un ejemplo claro de las "clases interactivas" propuestas por Hacking. La clase "gaucho" habría sido creada por miembros de lo que podríamos llamar la élite, es decir, personas capaces de crear e instalar dicha clasificación a partir del manejo de la producción cultural y su difusión y que contaban con lazos más o menos cercanos con los organismos de toma de decisiones, sin estar necesariamente ligadas a ellos directamente. ${ }^{7}$ Basándose en un conocimiento por lo general poco acabado de los habitantes rurales, esas élites crearon una "clase de gente" a la que denominaron "gaucho", que, por su amplitud, fue capaz de abarcar la multiplicidad de personas no propietarias que poblaban las pampas y que, desde entonces, comenzaron a ser consideradas ejemplos de un prototipo. ${ }^{8}$

Ese prototipo inspiró, a su vez, a viajeros extranjeros, que, en sus recorridos por las zonas rurales de la provincia de Buenos Aires, especial pero no exclusivamente, buscaron encontrar a ese personaje $y$, creyendo haberlo logrado en su interacción más o menos directa con diferentes sujetos, lo fijaron y reprodujeron, logrando afianzarlo aún más y ontribuyeron a su difusión, retroalimentando esa creación de las élites con las que, por otra parte, interactuaban, corroborando, las más de las veces, las ideas que ellas tenían de dicho prototipo. ${ }^{9}$

\footnotetext{
7 Es pertinente insistir en que "élite" no refiere, en este trabajo, a una clase social ni a la llamada "clase dominante". En cambio, se lo utiliza en el sentido que se da a este término en el marco de las teorías de élites funcionales: de aquí el plural que usamos para referirnos a esos grupos especializados y muchas veces interconectados (HARTMANN 2007, p. 22-40). En este caso, la élite cultural argentina de fines del siglo xIX podría considerarse un conjunto relativamente abierto a la "circulación" (en comparación a otras élites del país), con intereses diversos y muchas veces contrapuestos. Sin embargo, en el marco del tema que nos ocupa, el punto de vista manifestado por las élites, si bien cambiante, ha sido relativamente homogéneo. Es en razón de esta homogeneidad que se utiliza ese término para referirnos a esas minorías.

8 La relación entre el gaucho construido y los "ejemplares" concretos debería pensarse desde la noción de "clase radial" avanzada por Hacking (HACKING 1995, p. 24). No se trataría de una "escala" con un "gaucho ideal" en la cima e instancias más o menos cercanas a él con las que era posible interactuar, sino, más bien, de un "prototipo" en el centro y ejemplares a su alrededor, más cercanos o lejanos al centro cuanto más parecidos a él sean. Habría sido precisamente esta última característica la que permitió la amplitud a la que se alude. Es precisamente ese rasgo el que permitía a Sarmiento, por ejemplo, aludir con ese término a Rosas o a Facundo Quiroga, que de ninguna manera podrían considerarse "personas no propietarias": si bien, evidentemente, el prototipo de gaucho propuesto por él los excluiría prima facie, el hecho de que ambos compartieran una serie de características decisivas con aquél es lo que permite tipificarlos como tales.

${ }^{9}$ La utilización por las élites argentinas de los testimonios de viajeros extranjeros como cantera de ideas ha sido ya analizada (PRIETO 1996).
} 
Parte de las élites logró, a partir del ideario surgido en Facundo, atribuir al personaje así construido la responsabilidad por la resistencia del país a ingresar en la senda del "progreso", determinando que la extinción del gaucho era prioritaria para comenzar a transitarla, instando al Estado en conformación a tomar medidas en pos de ese objetivo. ${ }^{10}$

Así pueden establecerse: la "clase de gente" creada, es decir, el "gaucho" [elemento (a) en Hacking]; (b) las personas a las cuales afectaba dicha clasificación, los habitantes no propietarios de la pampa; (c) lo que el Estado debía hacer para lograr finalmente su desaparición y la evolución de la sociedad argentina; (d) un "saber" acerca del gaucho que se repetía interminablemente en las producciones culturales de (e) los "expertos" sobre ellos, élites y viajeros, en los que nos centraremos fundamentalmente aquí. Pero, nuevamente, la elaboración elitista de esa "clase de gente" no podía permanecer ajena a las personas así clasificadas: en cierto momento, los "ejemplares" de esa clasificación se concibieron a sí mismos en esos términos y comenzaron a responder al prototipo creado, convirtiéndose de ese modo en "auténticos gauchos", productos de consumo turístico que, desde comienzos del siglo xx y hasta hoy, han habitado las estancias donde proveyeron de shows que permitieron a élites y viajeros $y$, en último término, a la sociedad argentina en su conjunto, verificar la existencia (ahora limitada) de esos personajes considerados (desde entonces) "curiosidades" de las pampas.

Por lo tanto, se podría determinar, con Hacking, que los gauchos no existían, 20 o no existían de la misma manera, antes de comenzar a ser así clasificados, es decir, aproximadamente a partir de $1845,{ }^{11}$ y que su existencia con los rasgos que tomó entonces fue posible cuando esa clasificación se extendió y cobró un sentido preciso, con la publicación del Facundo y, todavía más, luego de la caída de Rosas en 1852. En 1845, el "gaucho" no era una forma de ser un tipo de persona, pero, en 1913, conformaba todo un conglomerado de experiencias y formas de autocomprensión y de vida en sociedad que algunas personas, habitantes de zonas rurales principalmente, se atribuían a sí mismas (Cf. HACKING 2007, p. 299).

En cuanto al aspecto heurístico, se propondrá una nueva evaluación de las condiciones de posibilidad de la "redención" del gaucho a partir de comienzos del siglo xx. Se verá que la reivindicación del personaje formaba parte de una estrategia discursiva de las élites, tal como se definieron ya desde mediados del siglo XIX, al tiempo que se comenzó a proclamar la desaparición del personaje tradicional de las pampas. Se intentará demostrar que la desaparición del gaucho era una conditio sine qua non para que el progreso se creyera consolidado y que fue, por tanto, encarada desde las élites como una labor cultural de eliminación de la "clase de gente" creada a partir de la oposición al gobierno de Rosas

\footnotetext{
${ }^{10}$ Sobre el vínculo que ligaba a los intelectuales con la "burguesía en formación" que terminaría por controlar el Estado argentino en su período de consolidación (1862-1880), véase OSZLAK 1982, p. 9.

11 Desde luego, el término y la descripción habitual del personaje eran comunes ya antes. Sin embargo, la connotación que asumió a partir del Facundo, como se verá, será esencialmente diferente a la que se daba a los gauchos con anterioridad.
} 
propugnada por Sarmiento en el Facundo. Germinalmente aparecida en la obra del sanjuanino, esa labor encontrará su expresión más acabada con la caída de Rosas y marcará la posición política de una fracción de las élites argentinas hasta, por lo menos, la primera década del siglo xx, acabando por convertirse en un rasgo propio de esa "clase de gente", el gaucho, que comenzará a entenderse como representante de un ser en extinción.

Dos aspectos de la construcción del gaucho serán estudiados en el presente artículo: por un lado, se analizará el modo en que ese término fue cargado de un valor negativo a partir del Facundo, la oposición que tal propósito del sanjuanino tuvo dentro del rosismo y, finalmente, el fracaso de esa oposición. Desde la perspectiva hackingsiana de este trabajo, la creación de esa "clase de gente" involucraba a su vez un juicio de valor sobre la existencia de ese personaje en relación con el avance del país. A partir del último tercio del siglo XIX comienza una tendencia a revertir ese juicio de valor, por la que la clasificación establecida es modificada, perdiendo su connotación negativa. Así, desde entonces se comenzaba a crear la condición de posibilidad de su reivindicación posterior, en simultaneidad con una modificación profunda de la carga valorativa del término.

Por otro lado, se pretende analizar la idea concomitante de la "extinción" del gaucho. Se verá que ella fue producto coherente de lo que el término involucraba: poco después de la valoración precisa asociada al concepto con el Facundo, se comenzaría a proclamar la desaparición del personaje, simplemente considerando a esa "clase de gente" construida extinta. Sin embargo, precisamente esa caracterización llevó a que, interactuando con ese nuevo rasgo, ciertos habitantes no propietarios de las pampas se concibieran a sí mismos como últimos representantes de esa clase que se perdía, y esa reacción nos habilita a estudiar, desde los testimonios de las mismas élites, el "efecto bucle" de la clasificación establecida. Se verá asimismo que la propia idea de extinción conllevaba la de utilización literaria del gaucho, que se impondría hasta hacer de él un símbolo de la "identidad nacional" con El payador.

Corresponde enfatizar dos aspectos fundamentales del punto de vista del presente trabajo: en primer lugar, no pretende establecer que la existencia del gaucho fue una quimera sin correlato objetivo alguno, producto de la imaginación de las élites argentinas. Tal punto de vista es propio de un enfoque "construccionista" al que se trata aquí de evitar y superar a partir de la teorización de Hacking. Así, se analiza el proceso de creación de una "clase de gente" que luego sería tomada por algunas personas del ámbito rural para asumirse como tales, haciendo, efectivamente, "real" al gaucho.

En segundo término, este trabajo no pretende analizar el modo en que esas personas concibieron al gaucho ni el propósito con el cual se asumieron a sí mismas como representantes suyos. No es una historia de los "gauchos" mismos, ni pretende analizar cómo éstos se veían y entendían su lugar dentro de la sociedad: estudios de ese tipo se han realizado ya con resultados de gran interés (DE LA FUENTE 2000; CHASTEEN 1995). En cambio, pretende concentrarse en la imagen que las élites elaboraron de ese personaje y en los 
resultados que esa elaboración tuvo para algunos habitantes rurales a los fines de establecer, sin agotar, el modo en que se produjo el "efecto bucle".

\section{El trayecto del término}

En 1845, Sarmiento escribe y da a la prensa el Facundo, aparecido originalmente en un periódico chileno. De esta obra se pretende analizar únicamente la dicotomía que establece para la Argentina y eso sólo en la medida en que contribuye a aclarar el papel que la oposición a Rosas jugó en la nueva imagen que a partir de ese año, aproximadamente, comenzaron a construir las élites argentinas del gaucho.

Desde 1810 y hasta la asunción de Rosas como gobernador de Buenos Aires con poderes supremos (1835), el término "gaucho" había servido para nombrar genéricamente a todos los habitantes de la campaña (CONI 1969, p. 222-223). Sin embargo, y al calor de la lucha de facciones, "el vocablo "gaucho" se define cada vez más con pretextos esencialmente políticos, pues unitarios y federales quieren atraer los gauchos a su partido y empiezan a creer que no debe ser un obstáculo a su propósito el Ilamarlos así crudamente" (CONI 1969, p. 226).

Sarmiento rompe con ese esquema: al imponer la tajante distinción entre "civilización" urbana y "barbarie" rural, entre vida civil y caudillismos, el gaucho resultaba completamente excluido del país que el autor esperaba una vez superado Rosas. Así, al distanciar a la oposición de Rosas del gaucho, el autor sanjuanino identificaba al Restaurador y al federalismo in toto con él y con su "barbarie".

22 A partir de 1845 aparece la decisión de distinguir entre dos tipos de habitantes de la campaña. Al hacerlo, el federalismo parece querer desligarse de ese personaje entonces subvaluado. El rosismo, en particular, buscará matizar el término "gaucho" para librarlo de sus connotaciones negativas.

Podría considerarse ese proyecto de matización un "programa de imposición cultural" a tono con otras medidas características del período (WILDE 1960, p. 205). Es por ello que sólo aparecerá en obras escritas bajo el influjo, más o menos cercano, de Rosas o en el contexto del gobierno de la Confederación una vez caído el Restaurador.

En efecto, la primera aparición de esa distinción puede datarse en 1845.12 En un "vocabulario rioplatense" escrito por Javier Muñiz, aparentemente para uso del gobernador de Buenos Aires, el vocablo "gaucho" es definido como aplicable solamente a "campesinos" que "bien sirven como peones en la ganadería o en la labranza, se designa también con este nombre a todo campesino civil; también se les llama camiluchos y guasos" (VIGNATI 1937, p. 406). Aquellos habitantes de la campaña que "andan por los campos [...] solos o siempre alertas" o que deben una muerte son denominados "gauchos alzados" (VIGNATI 1937, p. 440). Para quienes viven "errantes, sueltos y sin domicilio, por lo general criminales

\footnotetext{
12 Estas matizaciones son indudablemente tardías en el rosismo y no pueden encontrarse con anterioridad en la prédica favorable al gobernador de Buenos Aires. Baste como ejemplo el sugestivo uso que del término hace un poeta gauchesco indiscutiblemente rosista, Luis Pérez: "Todos los paisanos vieron, / sin que duda les quedara, / que D. JUAN MANUEL era hombre / que en ninguna se turbaba. / Y ansí todos a una voz; / 'Quien gobierne la gauchada' / diciendo: 'ahora sí tenemos'" ("Biografía de Rosas", 1830, vv. 273-279, en RODRÍGUEZ MOLAS 1957).
} 
perseguidos por la Justicia o por la autoridad en virtud de deserción" se reserva el término de "gauchos netos": el autor se cuida de establecer que esa distinción es puramente lingüística; en efecto, por lo demás, ellos son "enteramente gauchos, sin que el vestir, montar, lenguaje y conducta aventurera desmienta en un ápice la calidad de gauchos".

Sin embargo, esa distinción parece sólo para satisfacción de Rosas mismo: en efecto, en correspondencia a un tal Enrique Lamb, Muñiz no la hace: "gaucho" y "gaucho neto" son equivalentes y sus costumbres, y sobre todo sus vicios, son descritos por lo general sin hacer salvedades (VIGNATI 1937, p. 436-444). Esos vicios ameritan, por otra parte, la persecución que de ellos hace Rosas y que amenaza ya con su extinción: en efecto, su "número ha disminuido considerablemente por la vigilancia del actual gobierno sobre el abigeato y en la policía de campaña" (VIGNATI 1937, p. 434).

Estos dos caracteres, a saber, distinción entre los gauchos asentados y aquellos otros, definidos como delincuentes, por un lado, y represión de estos últimos, por otro, será una constante en los relatos de viajeros correspondientes al período rosista. Ese mismo año de 1845, un viajero francés repite el distingo, sólo que denomina "paisanos" a los gauchos empleados y asentados (B*** 1876, p. XXIV). El término "gaucho", por lo demás, se asocia directamente tanto con las milicias rosistas (B*** 1876, p. 127, 148), utilizadas para la represión de delitos, como con los mismos perpetradores de éstos, gauchos aparentemente provenientes de la ciudad, enviados, es de suponer, por el mismo Rosas ( $\mathrm{B} * * *$ 1876, p. 119-120).

Dos años más tarde, el comerciante inglés William MacCann visita la Argentina. El autor, conforme con el trato dado a sus connacionales por el Restaurador, parece dar sus impresiones bajo influencia de la propaganda rosista. Aquí volvemos a encontrar la distinción ya vista, sólo que ahora sería "la masa del pueblo" la que habría prescindido del término "gaucho", reemplazándolo por "paisano": el primer vocablo, en efecto, no se refiere al "peón o trabajador criollo", sino que "designa un individuo sin domicilio fijo y que lleva una vida nómada" (MACCANN 1986, p. 116). También él nota que "merodeadores y ladrones" han sido casi del todo eliminados por el Restaurador mediante un "sistema" que consiste en aplicar "la pena capital a todos cuantos violan las leyes del país, sin distinción de clases" (MACCANN 1986, p. 122). La política de represión de aquellos "gauchos" no empleados por ningún estanciero, es decir, que permanecían al margen del mercado de trabajo de la época, surte efecto: para 1849, el gaucho ladrón ha desaparecido. Quien queda es un personaje característico por su honorabilidad (STRAIN 1853, p. 234-235).

Como se dijo, la distinción lingüística había sido presumiblemente implementada para satisfacción del propio Rosas. En primer lugar, el distingo de Muñiz vale solamente para la obra dirigida al Restaurador. Por otra parte, muy poco después de caído el líder, un periódico de Buenos Aires se refiere a la palabra "paisano" como un ejemplo de la "terminología rosista" que debía desterrarse (SLATTA 1983, p. 31). Finalmente, después de 1852, la sutil diferenciación entre ambos habitantes de la pampa, es decir, el "paisano" y el 
"gaucho", comienza a desvanecerse y sólo aquellos ligados al federalismo o a Rosas mismo la conservan.

En efecto, si ya en 1854 el término "gaucho" sirve a un viajero aparentemente desconectado de toda influencia directa del gobierno para referirse indistintamente a peones y dueños de estancias (BISHOP 1869), pocos años después, un extranjero convocado por la Confederación para hacer una descripción del país reserva el vocablo "paisano" para los peones, aclarando que, ya entonces, son llamados "impropiamente gauchos", ya que esa palabra sólo designa "en la campaña" al "hombre errante, al vagabundo sin lugar y sin familia", "sin otro bien que su ropa y su caballo" (DE MOUSSY 2005b, p. 270, 112). Si antes el "gaucho" era perseguido como ladrón y ajusticiado por el "sistema" de Rosas, ahora el término se utiliza para designar a aquel que es "enrolado por la fuerza en los cuerpos de línea", para distinguirlo del "paisano", que se considera soldado regular (DE MOUSSY 2005b, p. 113). Nuevamente, se trata de una distinción artificial, utilizada a los fines de poder perseguir y reprimir a un sector de los habitantes rurales. De hecho, las definiciones de "paisano" y "gaucho" que da el autor, como las que establecía el "vocabulario" dirigido a Rosas diez años antes, son prácticamente idénticas. Si uno trabaja "mal y de mal grado" y "perezosamente", considerando "un vaso de vino y sobre todo de caña, de vez en cuando una empanada [...] su regalo supremo, siempre que después tenga el placer de escuchar el rasguido [sic] de una guitarra..." (DE MOUSSY 2005a, p. 537), el otro "es el cantor de pulpería [...] quien, sentado a

24 la puerta [...] rasca la guitarra cantando con voz monótona [...] agrupando en torno suyo a los desocupados de los alrededores" (DE MOUSSY 2005b, p. 270).

La distinción, por lo demás, no tarda en olvidarse y el término que pasará a la historia como el utilizado para designar al habitante masculino de las pampas será el de "gaucho". Ya en 1861 "gaucho auténtico" es aquel que, aunque se desempeña, como el otro, en calidad de peón de estancia, se distingue de él por su "emancipada y altiva dignidad" (HINCHLIFF 1965, p. 156). Para 1893, "gaucho" y "paisano" pueden considerarse sinónimos (SLATTA 1983, p. 33), pero, en 1897, Fray Mocho se cree obligado a utilizar un vocablo diferente para referirse al que antes se habría denominado "gaucho neto": "matrero" (ÁLVAREZ 1960). El gaucho es ahora el peón de estancia por antonomasia. ${ }^{13}$ Así, cuando, cinco años después, un autor entone una queja por la extinción del gaucho, notará que "al gaucho de hoy sólo le agrada que le digan 'paisano', que quiere decir simplemente 'hijo del país', porque gaucho significa señor altanero y soberano, y el que se siente sereno y humilde en nuestra pampa" (LEZICA 1901, p. 295-296). Y la inversión de significado entre "gaucho" y "paisano" perdurará en el tiempo: en una obra publicada en 1942, un autor distingue entre el verdadero gaucho, el "más característico y atrayente habitante" de la Argentina y "su sucesor", "un pobre, miserable y

\footnotetext{
13 La única excepción que nos es conocida es la de L. V. Mansilla, que todavía en 1870 distingue entre el "paisano gaucho" y el "gaucho neto" (1993, 2, p. 486). Sin embargo, quizás podamos atribuir esa persistencia al rol de "alta política" que le estaba encomendado entonces o, más probablemente, a resabios de su pasado rosista (y a su parentesco con el Restaurador).
} 
mal pagado peón", notando que esa mala copia del gaucho, desprovisto de su dignidad, "es llamado paisano, pero nunca gaucho"14 (SLATTA 1986, p. 106, traducción nuestra).

Como puede verse, el término "gaucho" recorre un camino sinuoso: de designar simplemente a un habitante de las pampas, cobra un contenido despectivo con el Facundo de Sarmiento, al que el federalismo, y especialmente el rosismo, intenta oponerse con la introducción de matices al término o directamente mediante su reemplazo por "paisano". Este proyecto fracasa: la distinción entre "gauchos" y "paisanos" se olvida rápidamente cuando el influjo del Restaurador desaparece y ambos términos pasan a ser sinónimos. Sin embargo, y en medio del proyecto de reivindicación del habitante tradicional de las pampas, se retoma la discriminación entre "paisanos" y "gauchos", sólo que ahora es este último el vocablo de honra, aunque los representantes del tipo se consideren escasos o inexistentes.

Puede verse de ese modo que la carga semántica del término sufrió variantes según las diversas tendencias que lo utilizaran. Las élites y los viajeros construyeron la palabra según su comodidad y asignaron a ella diversos contenidos, es decir, un "saber" que, no por ser variable era menos útil para la construcción del prototipo. Los "expertos" creaban su campo de estudio y establecían una clasificación cuyos sujetos cambiaban a medida que ellos precisaban su contenido. Recién hacia finales del siglo XIX podía considerarse el camino recorrido en su totalidad, cuando el gaucho pasa a ser un personaje honorable y representativo del país.

Simultáneamente, como se verá a continuación, esas mismas élites daban por extinto al gaucho y los sujetos que se identificaban con esa "clase de gente" comenzaban una reivindicación de su identidad.

\section{La extinción del gaucho}

Luego de la derrota del rosismo, el gaucho, considerado ahora como un personaje dañino para el futuro del país y que parecía nacer entonces, debía desaparecer. Y, efectivamente, ese plan pareció exitoso; los estudios histórico-fácticos sobre el gaucho lo demuestran:

El pobre gaucho empieza a darse cuenta que los tiempos ya no son los de antes; de todos lados lo empujan, lo echan. Casi no hay ya baldíos o realengos para levantar su rancho primitivo; los gringos y porteños ricos lo ocupan todo [...] unos puesteros vascos [...] guardan la hacienda y ya no se puede carnear a discreción (CONI 1969, p. 312-313).

Estas palabras se entroncan en una tradición extensísima. Los dos motivos en que se basa, el progreso (implícito en la aclaración de que "los tiempos ya no son los de antes") y el advenimiento de la inmigración, sintetizan otras tantas posiciones complementarias que se tomaron respecto de las causas de la desaparición del gaucho.

\footnotetext{
${ }^{14}$ En el original: "[...] is called paisano, but never gaucho".
} 
Los proyectos imaginados para la Argentina posterior a Rosas analizados por Tulio Halperín Donghi involucraban la desaparición del gaucho como un requisito y no simplemente como un efecto. ${ }^{15} \mathrm{Si}$ el gaucho es fruto de una clasificación, su desaparición puede decretarse a partir de una intención, sin necesidad de un hecho fáctico: simplemente, se debía eliminar esa "clase de gente" creada mediante esa clasificación por los "expertos", darla por extinta, para que el gaucho, inmediatamente, perdiera su existencia o, al menos, quienes se consideraban a sí mismos tales se concibieran como sobrevivientes, supérstites de un pasado más o menos remoto e irrecuperable. Se intentará emprender, entonces, un examen de la intención misma, de sus fuentes y su desarrollo, hasta el momento en que quienes la acariciaban la consideraron, por fin, cumplida.

La influencia que el relato del viajero inglés Francis Bond Head, quien recorrió las pampas a mediados de la década de 1820 (HEAD 1986), ejerció sobre los intelectuales argentinos, y especialmente sobre Sarmiento, puede difícilmente ser exagerada. Según Prieto,

La Edad Media convive en la Argentina, de acuerdo con Sarmiento, con la Moderna, y, aunque todavía en conflicto, el movimiento lineal del Progreso había jugado ya sus chances por la última. Con el uso de diferentes analogías y con una diferente medición del tiempo en el que el Progreso reclamaría su victoria, Francis Bond Head había asignado al gaucho el recorrido de la misma parábola. El gaucho, decía el viajero, figura tan interesante en tantos sentidos, presta un escaso servicio a la gran causa de la civilización, pero merece permanecer, sin censura, en las ilimitadas llanuras que habita, hasta que la población cree las necesidades de un mundo civilizado y provea los medios de suplirlos (PRIETO 1996, p. 171-172).

En las consideraciones del inglés así formuladas se encuentran los fundamentos de lo que Sarmiento expondrá en Facundo: la civilización, que necesariamente advendría al Plata, debía encargarse también de la remoción del habitante de las pampas. Sin embargo, se agrega en el sanjuanino un matiz nada menor: si para el viajero el gaucho "merece permanecer sin censura", Sarmiento proporciona en su obra los medios para lograr su extinción. No debe esperarse a que la civilización llegue a la Argentina: su arribo debe estimularse mediante la inmigración (AMBROSETTI 1893, p. 114). Y así, aparecen ya en él los dos elementos que se consideran fundamentales para la eliminación del personaje tradicional: inmigración y "progreso". Una vez alcanzados éstos, el gaucho necesariamente debía desaparecer, así como necesariamente la inmigración debía hacer civilizada la tierra que cultivara. Por otra parte, sería imposible considerar a un país "civilizado" mientras el tipo "bárbaro" del gaucho persistiera en las pampas, es decir, mientras la inmigración no lo subyugara y

\footnotetext{
15 "Es la conclusión que propone la generación de 1837, que Echeverría ilustra en El Matadero y que Sarmiento utiliza en Facundo para explicar las crisis de la Argentina posrevolucionaria: el primitivismo político que caracteriza a la confederación rosista revela en ella el fruto de la victoria de la barbarie pastoril sobre la civilización urbana. La eliminación del primitivismo socio-cultural de la campaña requiere la del predominio ganadero [...]. En esa noción se apoya entonces el vasto consenso que propone la colonización agrícola de la campaña como solución no sólo para el atraso de ésta sino para los problemas socio-políticos de la entera nación. Ese consenso no va a ser nunca recusado..." (HALPERÍN DONGHI 1980, p. LXXXIX).
} 
marginara. Se trata, como puede verse, de un razonamiento circular que servirá de apoyo para la proclamación de la extinción del gaucho a los pocos años: dada una de las condiciones, la otra seguiría indefectiblemente, sin importar por cuál se comenzara. La proclama de que el país progresaba podía, entonces, ser demostrada tanto por la llegada de la inmigración como por la desaparición del gaucho: ambas condiciones la presuponían, a la vez que se asumían mutuamente. Del mismo modo, el hecho de que la campaña "progresara" debía ser consecuencia tanto de los efectos de la inmigración como de la extinción del habitante tradicional de las pampas.

Teniendo esto en cuenta, el estudio de los abundantes testimonios de la eliminación del gaucho por la introducción de innovaciones técnicas dice menos sobre la condición concreta del gaucho que sobre las expectativas de las élites: en efecto, la aparición del extranjero, la parcelación de tierras con el paso a un modelo productivo agrícola y el "progreso" de la campaña, sobre todo, son causas de la desaparición del personaje típico, si no en lo efectivo, al menos en lo racionalmente esperable, y eso aun cuando sendas condiciones no eran cumplidas por el todavía "desierto" territorio argentino. ${ }^{16}$

Ambos elementos disolventes de la identidad gauchesca aparecen ya en 1860 en un viajero italiano: quienes desplazan al gaucho son "Ios genoveses, los españoles y, sobre todo, los habitantes de las Canarias". De todos modos, poca carne podían ya entonces utilizar los pintorescos habitantes de la pampa, y no de vacunos, por "el precio subido de los cueros y la escasez siempre mayor de ganados", ya que "la agricultura [...] va disputando trabajo al pastoreo" (MANTEGAZZA 1916, p. 75). En 1873, un periódico anuncia que el "bastardeo" del tipo gaucho es fruto del "contacto de la civilización que empieza a establecerse en la campaña" (MARTÍn FIERRO 1972, p. 233234) y, si diez años más tarde es el inmigrante el que fuerza al gaucho a cambiar "el chiripá y el calzoncillo de Santos Vega y de Calibar por la bombacha del oriente, y el chambergo, cuyas alas, quebradas de diferentes maneras, revelaban las tendencias de su carácter, por la roja boina de los vascos" (ZEBALLOS 1883, p. 19), para fines de siglo a los agentes del cambio se debe agregar "el camino de hierro" (CLEMENCEAU 1911, p. 153-154). ${ }^{17}$ Esta llegada masiva de extranjeros, sumada a la delimitación de terrenos por el alambrado, priva a la campaña de "incidentes pintorescos", forzando al gaucho a "perder su individualidad", asimilándose a las multitudes de europeos (CHILD 1902, p. 312-313, traducción nuestra), llevándolo a huir hacia el sur, hacia los campos antes ocupados por las tolderías de los indios. Poco hay que hacer, incluso "de ahí los va a desalojar pronto la ola invasora de la inmigración que avanza impertérrita" (QUESADA 1983, p. 134-135) todavía a comienzos de siglo. Esa sustitución del gaucho por el inmigrante corresponde, según Urien y Columbo (1910, p. 570) a "la ley natural que se cumple imponiéndose la fuerza inteligente sobre la fuerza bruta". El último

\footnotetext{
${ }_{16} \mathrm{Al}$ parecer, no lo habían sido ni siquiera mediada la primera década del siglo XX (WIBORG 1905, p. 104-108). 17 El motivo de la transformación del gaucho por la locomotora aparece en varias poesías de Rafael Obligado, como "La salamanca" y "La luz mala".
} 
reducto que quedaba al habitante de la campaña, el ejército, será rendido por la profesionalización bajo Roca, en 1890 (PRADO 1960, p. 56-57).

Ahora bien, esa apertura a la afluencia del "progreso" y la inmigración tendría, para Sarmiento, un inicio preciso: la caída de Rosas (SARMIENTO 1961 , p. 253). Y, en efecto, para 1870, Mansilla asegurará que "la Libertad, el progreso, la inmigración, la larga y lenta palingenesia que venimos atravesando hace dieciocho años lo va haciendo desaparecer [al gaucho]" (MANSILLA 1993, 2 , p. 489). Alfredo Ebelot es más preciso al atribuir al influjo de los unitarios la transformación de ese personaje desde hacía 30 años (es decir, nuevamente a partir de 1852), "a su imagen y semejanza. [...] El gaucho se transforma tan rápidamente como el país que vive" (EBELOT 1961, p. 47-48).

Así, las afirmaciones de que el gaucho desaparece comienzan a sucederse en una serie ininterrumpida y con fórmulas siempre similares a lo largo de un período inexplicablemente largo: en 1856, apenas salido el país del período rosista, Miguel Cané escribe su artículo "El gaucho argentino", que recién se publicará ocho años más tarde (CANÉ 1864). Allí asegura que, si "hace diez años que ese elemento de atraso y de desorden revestía aún su corteza salvaje, virginal: el fruto de otras necesidades, de otro orden de cosas, irá poco a poco gastando ese tipo que parecía perpetuarse por desgracia, en las generaciones venideras", en cambio "hoy no aparece ya sino como el pálido destello de una individualidad degenerada y carcomida".

En 1872, año, por otro lado, de la publicación de El gaucho Martín Fierro, La Nación advertía en un artículo titulado sugestivamente "El último gaucho" que la "visión [del gaucho argentino] no es frecuente en las mismas sendas campesinas trilladas en tan enorme extensión por la locomotiva, y parece haberse refugiado fuera del alcance de las causas que han de transformarlo un día en un figurín de modas" (MÍGUEZ; YANGILEVICH 2005, p. 79-80). Tres años después, y en lenguaje poético, se repite el motivo (ZABARÍA 1972, p. 236-237).

Nuevamente, en 1883, un viajero inglés profetiza que "por el crecimiento de la población y la consecuente limitación del territorio, las propensiones [...] del gaucho serán gradualmente reprimidas" (WHITE 1883, p. 73-74, traducción nuestra), lo que parece cumplirse alrededor de una década después. ${ }^{18}$ Pero, en 1902, Ernesto Quesada considera que su desaparición no se ha completado todavía (QUESADA 1983, p. 148) y, cuatro años después, un viajero asevera que el gaucho todavía "se va" y vuelve a predecir que "pronto, todos los cráneos se cubrirán del internacional, del universal sombrero de forma alta" (DONNET 1906, p. 190-191, traducción nuestra).

Recién a partir de la primera década del siglo XX comenzamos a notar una tendencia sostenida a dar al gaucho por extinto, en sospechosa simultaneidad con su "redención" definitiva con El payador, en cuanto a la carga semántica de la palabra: en efecto, ya en 1907, en un "estudio psicológico de los orígenes argentinos", Lucas Ayarragaray (1925, p. 50) atribuye su desaparición a la extensión de las condiciones

${ }^{18}$ A fines de siglo, Cortés D'Amico asegura que el gaucho "ya no existe, y hasta su nombre se va borrando del vocabulario especial de las campañas" (MÍGUEZ; YANGILEVICH 2005, p. 81). 
urbanas al campo. Lugones (1961, p. 106) se pronuncia por un diagnóstico similar en 1913 y, en 1915, en una teatralización del Martín Fierro,

[se] propone un truco escénico que entraña la interpretación simbólica de la idea central de la segunda parte del poema, su sentido didáctico. A tiempo que una voz entona la sextina de cierre del poema [...] el telón de fondo, trasparentándose, deja ver en perspectiva la silueta lejana de la ciudad que avanza (MARTÍN FIERRO 1972, p. 146).

Así, es posible adelantar, respecto a la extinción del gaucho, lo siguiente: construido como "clase de gente", el gaucho había asumido, con el Facundo, la característica fundamental de ser expresión del atraso del país. Decididas a proclamar el fin de aquél, las élites debían dar por eliminada a esa categoría: proceso simple, que, desde lo concreto, significaba desconocer a los ejemplares del prototipo como pertenecientes a la clase "gaucho" $y$, desde lo abstracto, proponer que el avance, real o supuesto, del país era la causa de ese desconocimiento. El proceso, sin embargo, no fue lineal: la extinción del personaje tradicional de las pampas aparece consistentemente sólo cuando se decide construirlo (o más bien reconstruirlo) como símbolo de la identidad argentina que se cree puesta en riesgo por una inmigración peligrosamente abundante.

Sin embargo, el plan que contempla el progreso argentino tiene otras aristas, además de la que involucra directamente la desaparición del gaucho: en efecto, ligada a ésta se halla una segunda área de interés que deja entrever la profundidad del proyecto de las élites respecto del futuro de la Argentina. El gaucho debía desaparecer, sí, pero, hacia 1851, Marcos Sastre percibía que no lo haría del todo:

Cuando los tipos poéticos de nuestra vida actual hayan desaparecido por la superposición de nuevas entidades y por la invasión de los hábitos e intereses de la vida civil e industrial, cuando nuestros desiertos y el hombre de nuestros desiertos [...] hayan cedido su lugar a la actividad acompasada material de nuestra grandeza futura, los cuadros y las creaciones del señor Ascasubi serán sin disputa la fuente, los antecedentes homéricos de nuestra futura literatura (ASCASUBI 1872, p. xx).

Así, cuando en 1854 Mitre (1972) canta la modificación de las condiciones imperantes en la pampa, no hace más que intentar obedecer a una expectativa de la intelectualidad argentina. Se trataba de erigir, a su debido tiempo (es decir, cuando, en "un día lejano" no existiera ya en la llanura), al gaucho en motivo de los cantos nacionales: Rafael Obligado (1976, p. 15-16) se interesará por este tema y, de hecho, compondrá con él su Santos Vega, completado en 1887. Sin embargo, ese pedido de que, para decirlo con un pensador tardío, el "estro del poeta" diera "presencia constante, comienzo, continuidad y fin de aquello que, para los argentinos será siempre memorable y de donde, si hemos de llegar a ser lo que somos, tenemos que extraer memoria y vida" (ASTRADA 1994, p. 94), se revela como un locus classicus más dentro de la prédica sobre la extinción del gaucho: ya veinte años antes Cané había predicho exactamente lo mismo (CANÉ 1864, p. 664) y, en la última década del siglo, se reiterará aún 
la misma profecía (SCALABRINI 1894, p. 270-271). Rubén Darío cantaba a la Argentina, todavía en 1910, que "el gaucho tendrá su parte / en los jubileos futuros, / pues sus viejos cantares puros / entrarán en el reino del Arte. / Se sabrá por siempre jamás / que, en la payada de los dos / el vencido fue Satanás / y Vega el payador de Dios" (PRIETO 1988, p. 140, n. 59), versificando el motivo una vez más.

Para comienzos del siglo $x \mathrm{x}$, el gaucho, desaparecido en las pampas, se reconvirtió en motivo poético. Indudablemente, el éxito había coronado el plan de extinción que habían propugnado las élites a lo largo de más de 50 años. El personaje designado por la palabra "gaucho" ya se encontraba considerablemente diferenciado de las personas a las que, en algún momento, se había llamado de esa manera. Todavía entonces se podía aplicar ese término a algunos habitantes rurales, pero no sin aclarar que se trataba solamente de "peones ordinarios encargados de las faenas de la estancia", que, por si fuera poco, ya no vestían al modo tradicional: tal indumentaria se consideraba tan ridícula como para ser vista sólo en los carnavales (HURET 1952, p. 55-57). Pero aun los que decidieran seguir vistiendo a la vieja usanza no podían esperar, en 1926, ser llamados gauchos, sino, a lo más, ser vistos como ejemplos de "la presencia viva y marginal de los vástagos del gaucho en el medio rural" (GIAUDRONE 2008). ${ }^{19}$

A su vez, esa eliminación desde el discurso de la "clase de gente" gaucho conllevaba nuevas condiciones de posibilidad para la existencia de los habitantes tradicionales de las pampas. La creación de una clasificación que les 30 había permitido concebirse a sí mismos como gauchos había, probablemente, modificado su visión sobre su propia realidad: si ya no había muchos de ellos en las zonas rurales, eso los transformaba en sobrevivientes. Así, la extinción del gaucho pasaría a implicar, para algunos, no su desaparición concreta, sino simplemente una característica más de la clasificación de la que se sentían parte: se convertirían, entonces, en "auténticos gauchos", personajes que resistían el paso del tiempo y se apegaban a su esencia tradicional aun a pesar de las condiciones adversas del contexto. De ese modo se habría producido el "efecto bucle" en la clasificación del gaucho: la insistencia de las élites y los viajeros sobre su extinción habría llevado a la asunción de habitantes no propietarios de las pampas de las características atribuidas al personaje tradicional, transformándose ellos mismos, así, en "testimonios vivientes" de ese habitante legendario que se perdía. Esto, inmediatamente, abría para ellos "nuevas oportunidades de acción" (HACKING 1995, p. 239), nuevas formas de ser gauchos que hasta entonces habrían resultado inconcebibles. ${ }^{20}$ En efecto, ahora su labor habitual se encontraba abierta a nuevos significados, a ser interpretada de una manera predecible y determinada por sus espectadores. Las tareas de estancia eran ahora, para los testigos, parte del trabajo "gauchesco" y, por ello, atractivas. Así

\footnotetext{
${ }_{19}$ Sin embargo, comparando la foto de uno de éstos (GIAUDRONE 2008, figura 5) con las imágenes tradicionales del gaucho "real" (por ejemplo, GIAUDRONE 2008, figura 2), resulta muy difícil establecer un criterio de distinción objetivo.

20 Preferimos considerar de esta manera las supervivencias del gaucho y no al modo de "resistencias" populares contra la "alta cultura", como lo hacen Eujanian y Cattaruzza (2003).
} 
surge el gaucho como atractivo turístico: la imposibilidad (cierta o imaginada) de ver esos actos de la rutina rural en su "ámbito natural" hace que los viajeros estén dispuestos a pagar por observarlos. De esa forma aparecerán números de tradición en chacras que agasajan a los visitantes con asado con cuero, puchero y champán, en los que, y "para que se guardasen todos los pormenores de una legítima comida popular [...] dos payadores entonaban, alternadamente [...] estrofas populares en homenaje a no sé qué otro payador célebre del cancionero local" (DIAS 1901, p. 306-307), o demostraciones de la habilidad en faenas rurales del personaje en lugares como el Palermo Cattle Show (ALCOCK 1907, p. 246). Previamente a ese "efecto bucle" el término "gaucho" no habría apelado a los habitantes no propietarios de las pampas y, de hecho, sus habitantes no propietarios no asumían para describirse a sí mismos ese término; luego de dicho efecto, podemos afirmar con seguridad que un grupo de ellos se sentía identificado con ese nombre y lo reivindicaba orgullosamente como propio.

Esas nuevas formas de ser gaucho darían paso a su popularización como portadores de identidad colectiva en una sociedad que aparecía como heterogénea: el gaucho podría entonces aparecer como personaje circense en espectáculos presentados por una compañía de italianos (SIMOENS DA SILVA 1910, p. 265-268) o como protagonista de películas que podían llegar a proyectarse en la lejana Esmirna (BIOY 1998, p. 222).

\section{Conclusión}

Este trabajo tuvo como objetivo principal el de analizar la construcción que las élites, tal como han sido definidas aquí, hicieron del gaucho durante el período que media entre la publicación del Facundo y las conferencias que dieron como resultado El payador.

Se partió de la base de que esa construcción consistió en la creación de una "clase de gente", tal como esa construcción ha sido denominada por Ian Hacking. En este caso, habría nacido la clasificación de "gaucho", efectuada por un grupo determinado, las fracciones productoras de cultura en la sociedad argentina y los viajeros extranjeros en estrecha relación con ellas, que tuvieron lazos más o menos directos con las medidas que adoptaría el Estado durante ese período para conseguir uno de los fines que aparecían como primordiales para la constitución de una nación moderna en el "desierto argentino": la extinción de ese personaje típico de las pampas.

La construcción del habitante tradicional de las pampas como un prototipo del "atraso", iniciada por Sarmiento y continuada, aunque no sin oposición, hasta el fin del período rosista, llevó a considerar a ese personaje como un mal del que el país debía deshacerse para lograr su evolución. Así, en la creación de la clasificación del gaucho como una "clase de gente" se encontraba implícita su desaparición como condición de posibilidad del progreso de la Argentina.

Una vez que el rosismo fue desplazado, el fin de las disputas sobre el significado del término "gaucho" y la puesta en marcha de medidas que desembocarían en la modificación de las condiciones productivas de la campaña fueron simultáneos. Sin embargo, la consecuencia esperada de esas medidas en 
cuanto al gaucho se dio demasiado inmediatamente, aunque, paradójicamente, también fue postulada de manera sospechosamente idéntica durante más de 50 años. Por más de medio siglo, el gaucho estuvo desapareciendo o su extinción definitiva fue inminente.

Relacionando ambos aspectos analizados, es decir, la imposición sobre el vocablo "gaucho" de un significado despectivo y contrario al avance de la civilización iniciado por el Facundo y su posterior reivindicación a comienzos del siglo XX, por un lado, y la persistencia en la prédica de su extinción desde 1851 en términos muy semejantes y su éxito final hacia el mismo cambio de centuria, por otro, es posible suponer que los dos tenían más que ver con una clasificación abstracta de "clase de gente" que con la existencia "real" de los habitantes tradicionales de las pampas. La "redención" del gaucho y su desaparición son sospechosamente simultáneas y la supuesta relación que se establece entre ellas de causa (extinción) y efecto ("redención") puede ser discutida. Podría muy bien ser que la causa fuera la intención de las élites de lograr la reivindicación del personaje y que, para ello, debiera necesariamente seguirse el efecto, es decir, su desaparición definitiva. Así, ambos eventos pueden ser vistos como partes de un mismo proceso de construcción, el que conforma la clasificación del gaucho como una "clase de gente", desligado de la existencia efectiva de ese personaje.

Sin embargo, esa falta de lazos entre la clasificación y los sujetos así clasificados no fue tal. Algunos pobladores de la zona rural se asumieron como miembros de esa "clase de gente" $y$, partiendo precisamente de su condición de

32 seres excepcionales en cuanto extintos o próximos a desaparecer, comenzaron a actuar en consecuencia, decidiendo adherirse a prácticas que hasta ese momento aparecían como inconcebibles para los habitantes tradicionales de las pampas, abriendo las puertas para su transformación en atractivo turístico del país, lugar que tienen todavía hoy, produciendo de hecho un "efecto bucle", según la denominación de Hacking. Esto no implica, en manera alguna, que los sujetos de dicha clasificación sólo se entendieran como gauchos a partir de fines del período considerado. Pero es sólo a partir de comienzos del siglo xx que esa reacción se ve atestiguada en las fuentes aquí analizadas, las producidas por las élites y los viajeros.

Este trabajo, por lo demás, forma parte de un proyecto más amplio de análisis del modo en que las élites construyeron a ese personaje típico, que se concentra en otros aspectos del mismo período, como el uso por las élites argentinas de la poesía gauchesca como instrumento de construcción del gaucho y el proceso por el que finalmente ese personaje fue "redimido" para poder actuar como portador de identidad que lograra aglutinar a una sociedad cada vez más heterogénea en los comienzos del siglo xx en Argentina.

\section{Referencias bibliográficas}

ALCOCK, F. Trade and Travel in South America. Liverpool: George Philip \& Son, 1907.

ÁlVAREZ, José C., Tierra de Matreros. Buenos Aires: Eudeba, 1960 [1910]. 
AMARAL, Samuel. Trabajo y trabajadores en Buenos Aires a fines del siglo XVIII. Anuario IEHS, n. 2, p. 33-41, 1987.

AMBRoseTtI, Juan Bautista. Viaje a la Pampa Central. Buenos Aires: Biedma, 1893.

ASCASUBI, Hilario. Santos Vega o los Mellizos de la Flor. Paris: Paul Dupont, 1872.

ASTRADA, Carlos. EI Mito Gaucho. Buenos Aires: Secretaría de Cultura/Catari, 1994.

AYARRAGARAY, Lucas. La Anarquía y el Caudillismo. Buenos Aires: Lajouane y Cía., 1925.

B***, Armand de. Mes Voyages avec le Docteur Philips dans les Républiques de La Plata. Tours: Mame et Fils, 1864.

BARR MELEJ, Patricio. Cowboys and Constructions: Nationalist Representations of Pastoral Life in Post-Portalian Chile. Journal of Latin American Studies, v. 30, n. 1, p. 35-61, 1998.

BIOY, Adolfo. Años de Mocedad. Buenos Aires: Guías de Estudio, 1998 [1963].

BISHOP, N. H. The Pampas and the Andes. Boston: Lee \& Shepard, 1869.

BOSCH, Beatriz. Estudio Preliminar. In: CONI, Emilio. El Gaucho. Buenos Aires: Solar/Hachette, 1969.

CANÉ, Miguel. El Gaucho Argentino. Revista de Buenos Aires, v. 2, n. 17, p. 658-664, 1864.

CHASTEEN, John Charles. Heroes on Horseback: a life and times of the last gaucho caudillos. Albuquerque: University of New Mexico Press, 1995.

CHEIN, Diego J. Escritores y Estado en el Centenario: apogeo y dispersión de la literatura nativista argentina. Revista Chilena de Literatura, n. 77, p. 51-73, 2010.

CLEMENCEAU, Georges. Notas de Viaje por la América del Sur. Traducido por M. Ruiz. Buenos Aires: Cabaut y Cía, 1911.

CONI, Emilio A. El Gaucho. Buenos Aires: Solar/Hachette, 1969.

DE LA FUENTE, Ariel, Children of Facundo. Caudillo and Gaucho Insurgency during the Argentine State-Formation Process (La Rioja, 1853-1870). Durham: Duke University Press, 2000.

DE MOUSSY, V. Martin, Descripción Geográfica y Estadística de la Confederación Argentina. Buenos Aires: Academia Nacional de la Historia, 2005a [1864]. Tomo I.

DE MOUSSY, V. Martin, Descripción Geográfica y Estadística de la Confederación Argentina. Buenos Aires: Academia Nacional de la Historia, 2005b [1864]. Tomo II. 
DELANEY, Jeane. Making Sense of Modernity: Changing attitudes toward the inmigrant and the gaucho in turn-of-the-century Argentina. Comparative Studies in Society and History, v. 38, n. 3, p. 434-459, 1996.

DIAS, A. Do Rio a Buenos-Aires. Episodios e Impressões d'uma viagem. Rio de Janeiro: Imprensa Nacional, 1901.

DONNET, Gaston. De I'Amazone au Pacifique, par le Pampa et les Andes. Paris: Delegrave, 1906.

EBELOT, Alfredo. La Pampa. Buenos Aires: Eudeba, 1961 [1889-1890].

EUJANIAN, Alejandro; CATTARUZZA, Alejandro. Héroes Patricios y gauchos rebeldes. In: Políticas de la Historia. Argentina, 1860-1960. Buenos Aires: Alianza, 2003, p. 217-262.

GARAVAGLIA, Juan Carlos. ¿Existieron los gauchos? Anuario IEHS, n. 2, p. $42-$ $52,1987$.

; GELMAN, Jorge. Rural History of the Rio de la Plata: Results of a historiographical renaissance. Latin American Research Review, v. 30, n. 3, p. 75-105, 1995.

GELMAN, Jorge, ¿Gauchos o campesinos? Anuario IEHS, p. 53-59, 1987.

El gaucho que supimos conseguir. Determinismo y conflictos en la historia argentina. Entrepasados, n. 9, p. 27-37, 1995.

34 GIAUDRONE, Carla. El gaucho en el ámbito inconográfico del Centenario uruguayo (1925-1930). Revista Hispánica Moderna, v. 61, n. 2, p. 149-165, 2008.

HACKING, Ian. Kinds of People: Moving Targets. Proceedings of the British Academy, n. 151, p. 385-318, 2007.

Mad Travelers. Reflections on the Reality of Transient Mental Illnesses. Charlottesville: University of Virginia Press, 1998.

Rewriting the Soul: Multiple Personalities and the Sciences of Memory.

Princeton: Princeton University Press, 1995.

- The Social Construction of What? Londres: Harvard University Press, 1999.

HALPERÍN DONGHI, Tulio. Proyecto y Construcción de una Nación (Argentina 1846-1880). Caracas: Biblioteca Ayacucho, 1980.

HARTMANN, Michael. The Sociology of Elites. New York: Routledge, 2007 [2003].

HEAD, Francis B. Las Pampas y los Andes. Buenos Aires: Hyspamerica, 1986 [1826].

HINCHCLIFF, Thomas W. Viaje al Plata en 1861. Traducido por J. L. Busaniche. Buenos Aires: Solar/Hachette, 1965 [1863]. 
HURET, Jules. La Argentina. Buenos Aires: Espasa-Calpe, 1952 [1911].

JONES, Katherine L. Nineteenth Century British Travel Accounts of Argentina. Etnohistory, v. 33, n. 2, p. 195-211, 1986.

LEZICA, Juan José. Lo que dice un gaucho viejo. Revista Nacional, n. 31, 1901.

LUGONES, Leopoldo. El Payador. Buenos Aires: Centurión, 1961.

MACCANN, William. Viaje a Caballo por las Provincias Argentinas. Traducido por J. L. Busaniche. Buenos Aires: Solar/Hachette, 1986.

MANSILLA, Lucio V. Una Excursión a los Indios Ranqueles (Vol. 2). Buenos Aires: Espasa-Calpe, 1993 [1870].

MANTEGAZZA, Pablo. Viajes por el Río de la Plata y el Interior de la Confederación Argentina. Traducido por J. Heller. Buenos Aires: Coni, 1916.

MARTÍN FIERRO: un Siglo. Buenos Aires: Xerox, 1972.

MAYO, Carlos. Sobre peones, vagos y malentretenidos: el dilema de la economía rural rioplatense durante la época colonial. Anuario IEHS, n. 2, p. 25-32, 1987.

MÍGUEZ, Eduardo; YANGILEVICH, Melina. El Mundo de Martín Fierro. Buenos Aires: Eudeba, 2005.

MITRE, Bartolomé. A un ombú en medio de la pampa. In: BECCO, Héctor J.

Antología de la Poesía Gauchesca. Madrid: Aguilar, 1972, p. 16431645.

OBLIGADO, Rafael. Independencia literaria. In: BARCIA, Pedro L. Prosas. Buenos Aires: Academia Argentina de Letras, 1976.

OLIVEN, Ruben G. À la recherche des origines perdues: le mouvement traditionaliste gaúcho au Brésil. Études Rurales, n. 163/164, p. 145$165,2002$.

. The Largest Popular Culture Movement in the Western World: Intellectuals and Gaúcho Traditionalism in Brazil. American Ethnologist, v. 30, n. 1, p. $128-146,2000$.

OSZLAK, Oscar. La Formación del Estado Argentino. Buenos Aires: Editorial de Belgrano, 1982.

PRADO, Manuel. La Guerra al Malón. Buenos Aires: Eudeba, 1960.

PRIETO, Adolfo. El Discurso Criollista en la Formación de la Argentina Moderna. Buenos Aires: Sudamericana, 1988.

Los Viajeros Ingleses y la Emergencia de la Literatura Nacional. Buenos Aires: Sudamericana, 1996.

QUESADA, Ernesto. El "Criollismo" en la literatura Argentina. In: RUBIONE, A. V. 
En Torno al "Criollismo". Textos y Polémica. Buenos Aires: CEAL, 1983. RODRÍGUEZ MOLAS, Ricardo. Luis Pérez y la Biografía de Rosas escrita en verso en 1830. Buenos Aires: Clío, 1957.

SARMIENTO, Domingo F. Facundo. Buenos Aires: Eudeba, 1961 [1845].

SCALABRINI, Angelo. Sul Rio della Plata. Como: Ostonelli, 1894.

SIMOENS DA SILVA, A. C. Viagem pelo Interior da República Argentina. Rio de Janeiro: Imprensa Nacional, 1910.

SLATTA, Richard W. El Gaucho y el Ocaso de la Frontera. Buenos Aires: Sudamericana, 1983. . The Demise of the Gaucho and the Rise of Equestrian Sport in Argentina. Journal of Sport History, v. 13, n. 2, p. 97-110, 1986.

STRAIN, I. G. Sketches of a Journey in Chili and the Argentine Provinces in 1849. New York: H. H. Moore, 1853.

URIEN, C. M.; COLUMBO, E. La República Argentina en 1910. Buenos Aires: Maucci, 1910.

VIGNATI, Milcíades A. El Vocabulario rioplatense de Francisco Javier Muñiz. Separata del Boletín de la Academia Argentina de Letras, n. 5, p. 393-453, 1937.

WHITE, E. M. Cameos from the Silver-Land, or Experiences of a Young Naturalist in the Argentine Republic (Vol. 2). London: J. Van Voorst, 1883.

WIBORG, Frank. A Commercial Traveller in South America. New York: McClure, Phillips \& Co, 1905.

WILDE, José Antonio. Buenos Aires desde Setenta Años Atrás. Buenos Aires: Eudeba, 1960 [1881].

ZABARÍA, J. M. Martín Fierro. In: MARTÍN FIERRO: un Siglo. Buenos Aires: Xerox, 1972, p. 236-237.

ZEBALLOS, Estanislao. Descripción Amena de la República Argentina. Vol. 2. Buenos Aires: Peuser, 1883. 